\section{Material World 95 Brings Science to School Children}

In 1994 members of the University of Rochester Chapter of the Materials Research Society (URCMRS) successfully organized The Material World: a science day hosting 52 minority members of the Girls Scouts of America from the sixth through the eighth grades. ${ }^{1}$ Our motivation was to introduce these students to science before they may be prejudiced by myths stereotyping science as difficult, boring, and "geeky." The overall feedback from the girls was extremely positive. Organizing and presenting this event allowed URCMRS members to gauge which demonstrations were popular and which concepts were too advanced for the 11-13-year age group. Tapping from this knowledge, on May 13, 1995, we implemented our second Material World science day with help from the University of Rochester's Genesee Brooks Renewal Project and the Department of University and Community Affairs. ${ }^{2}$ We invited approximately 30 sixth-grade students from Rochester's inner city elementary schools. The goal of the science day was to offer the students a glimpse of how science contributes to and significantly transforms our lives and the world around us. We wanted to ignite a long-lasting, science-related interest in these children alongside offering them an opportunity to interact with scientists.

The first Material World consisted of five science stations, of which two involved hands-on activities, followed by a panel discussion with local woman scientists and graduate students. Lasers, optics, and superconductivity formed the primary focus of three demonstrations. The students performed simple reactions to learn about polymers and crystals. After the day-long event we asked the participants to respond to six questions on an evaluation form:

- Did you have fun?

- What did you learn?

- What did you like best?

- What did you like least?

- What one thing would you change if you could?

- What other types of programs would you like us to offer?

The statistics of 50 responses are illustrated in the figure. We were encouraged to know that over $90 \%$ had fun while learning science. The girls chose the laser demonstration as the favorite science station followed by the polymers, physics (optics and superconductivity), and crystals activities with $48 \%, 28 \%, 16 \%$, and $12 \%$ of their votes, respectively. However the statistics on least-liked demonstrations did not entirely match those for the mostliked. Sixty-four percent of the respondents least liked the physics station in contrast to only $6 \%$ disliking the crystals one. Overall, we clearly needed to alter the format and content of the physics demonstration. The students may have felt that some of the newly introduced concepts were too abstract. About $25 \%$ of the girls indicated that they wanted more hands-on participation; $16 \%$ wanted biology-related experiments. In addition, the audience barely participated in the panel discussion at the end of the day, which made that another activity to reorganize. On the whole, students and organizers enjoyed an exciting and unique experience while URCMRS gathered valuable suggestions to improve the science day.

In this past year we attempted to incorporate suitable changes to the Material World. We removed the focus from women in science, invited sixth graders from inner city schools, and replaced the panel discussion. About 30 students participated. We literally started the day with a bang, enthralling our audience with a half-hour-long display of explosions including a chemical volcano, contact explosives, a chemical fuse, and a thermite reaction. The students greatly applauded the loud sounds and bright lights. A commentary preceeded each display, describing the process responsible for the detonation as well as its industrial uses.

Next, the audience was divided into four groups and rotated through four different science stations. We made minimal changes to the laser and polymer demonstrations. We introduced a Science and Soap Bubbles station. Here, the students shaped pipe cleaners into unusual bubble holders. They dipped these into soap solution to create odd bubbles including caterpillars and cubes. A graduate student explained the geometry, chemistry, and optics of these soapy novelties. We also altered the Material World 94 physics demonstrations into a Physics Pot-Pourri consisting of a variety of small demonstrations illustrating various physical phenomena. The students learned about forces between electrical charges and investigated electricity with a Van de Graaf generator. Magnetism and its effect on different materials were depicted. They also studied phase changes in water and liquid nitrogen.

After lunch, Nicholas Bigelow, a professor from the Department of Physics and Astronomy at the University of Rochester, led a forum on science and career opportunities in science and engineering. He encouraged the students to

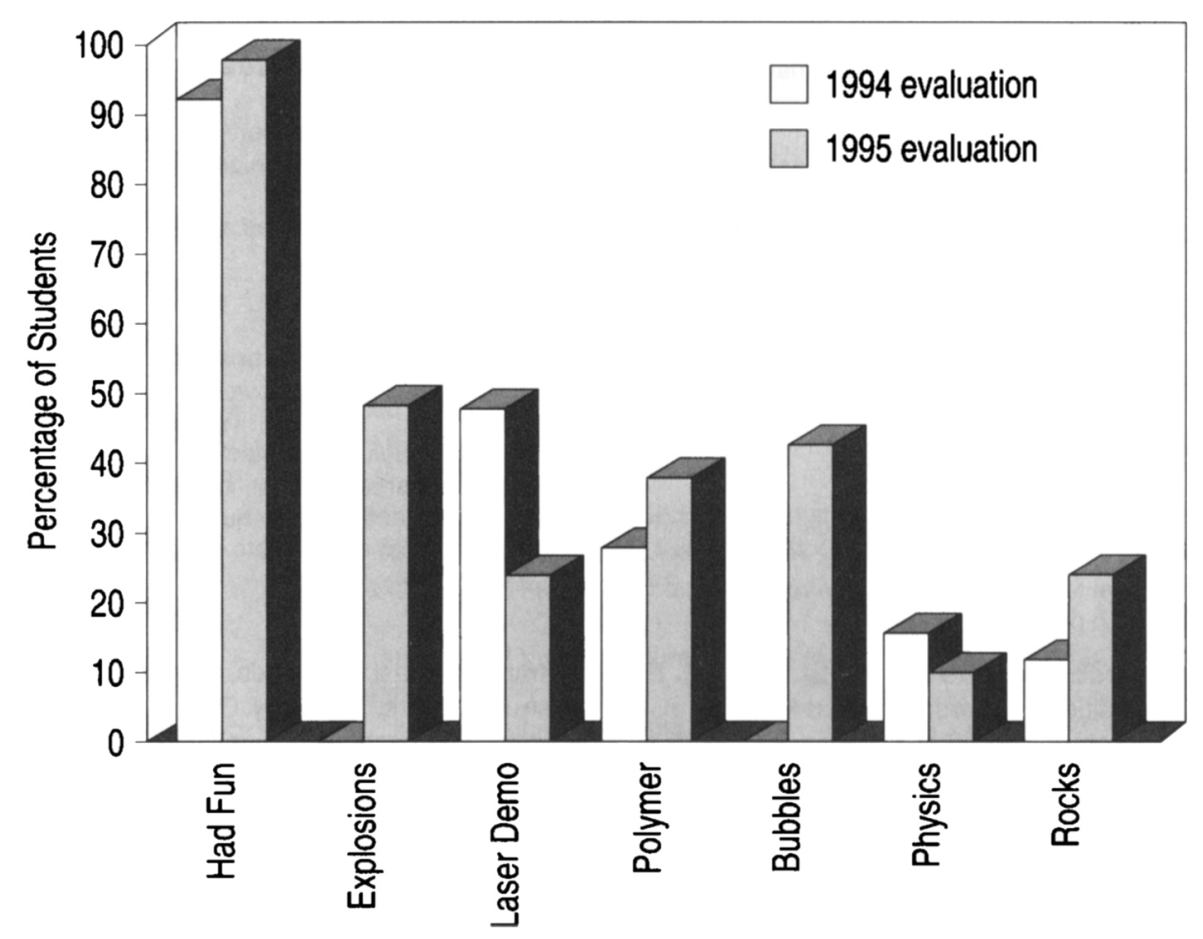

Statistics from student evaluations indicate how many students had fun and which demonstrations they liked most. 
ask questions as well as to answer each other's questions. He also spoke about his research on atom cooling and trapping at a level appropriate for the audience. The sixth graders interacted actively with the professor and among themselves. After this discussion, we concluded the day with a last hands-on activity on crystal growth. We had retained this experiment from Material World 94 since it demanded active student participation.

Twenty-one students completed the same evaluation form we had used the previous time (see figure). This time each and every student responded positively about having fun. In fact one response specified, "Yes, I would love to come everyday." We were surprised that the laser demonstration was not as popular as it was previously. It probably lost its novelty since laser shows have become commonplace. Explosions, soap bubbles, and polymers were a definite success. Though the detonations did not involve active participation of the students, the booms, bangs, sparks, and smoke captured their attention. The least appreciated science station remained the Physics Pot-Pourri. The students once again voiced their preference for hands-on

\section{Advanced Metalization and Interconnect Systems for ULSI Applications in 1996}

\section{October 1-3, 1996 in Boston, Massachusetts ANNOUNCEMENT AND GALL FOR PAPERS}

The conference is the thirteenth in a series organized to bring together active researchers in the field of advanced metalization for IC applications.

PAPERS ARE SOLICITED on topics in the deposition, processing, applications, and all aspects of conventional metalization:

\section{Metalization science}

Deposition chemistry and kinetics

Fundamental gas phase and surface chemistry

Nucleation and adhesion studies

Process modeling

Interfaces and film properties

Grain structure and surface analysis

Film/substrate interactions

Diffusion barriers

Contact resistance characterization

New materials

Low-k dielectrics (SOGs, polymers, porous oxides, etc.)

High-k dielectrics (BSD, PZT, tantalum pentoxide, etc.)

Low resistivity/high reliability metals (new Al alloys/silicides, $\mathrm{Cu}$, etc.)

Deposition methods

CVD metals and dielectrics

PVD metal and dielectrics

Electrochemical and chemical deposition

Selective metal deposition

High temperature deposition/reflow

High pressure extrusion

Abstracts are due July 1, 1996. Send abstracts (at least 500 words, with additional figures) to Robert Havemann, Texas Instruments, Inc., 13536 N. Central Expressway, MS 461, Dallas, TX 75243. Include author's name, affiliation, mailing address, and phone and fax numbers on abstract.

For an announcement: Call $(510) 642-4151$, fax (510) 643-8683, e-mail course@garnet.berkeley.edu, or write to Continuing Education in Engineering, University Extension, University of California, 1995 University Ave., Berkeley, CA 94720-7010.

Continuing Education in Engineering, University Extension, UNIVERSITY OF CALIFORNIA, BERKELEY activities. They also contributed other implementable ideas in terms of what programs they would like us to offer. Their suggestions included experiments in which they help graduate students, computer-related work, more explosive demonstrations, and visiting college students on a weekly basis.

SABRINA DIOL

1. See Julie Rehm's article for Education Exchange in MRS Bulletin, December 1994, p. 61. 2. We gratefully acknowledge the help of the University of Rochester's Genesee Brooks Renewal Project and particularly Judy Abelman, the Associate Director of University and Community Affairs. Our special thanks go out to the numerous University of Rochester graduate students, including Karen Moore, Paul Rodney, Emile Ettedgui, Al Heany, Andrew Ryan, Marie Inman, George Fischer, Eileen Korenic, and Michal Freedhoff (URCMRS President 1994-1995), to mention a few who cheerfully volunteered their time, skill, equipment, and patience to the realization of Material World.

Send MRS University Chapter and Section News to: Editor, MRS Bulletin, Materials Research Society, 9800 McKnight Road, Pittsburgh, PA 15237-6006. Fax 412-367-4373; e-mail Bulletin@mrs.org.

\section{The MrS Special Projects Subcommittee \\ offers financial assistance to University Chapters and Sections, and is continuously looking for proposals. \\ For more information, call membership services at 412-367-3003 or send e-mail to info@mrs.org.}

\section{Look for career-related programming from the Materials Research Society!}

The newly formed Employment Services Task Force is currently evaluating ideas on how to improve these services for membership. If you have an idea, or would like to volunteer your time, please e-mail info@mrs.org.

Circle No. 30 on Reader Service Card. 